\title{
Campylobacter upsaliensis exerts a cytolethal distending toxin effect on HeLa cells and $T$ lymphocytes
}

\author{
A. Mooney, M. Clyne, T. Curran, D. Doherty, B. Kilmartin and B. Bourke
}

Author for correspondence: B. Bourke. Tel: +353 1 4556901. Fax: +353 14555307.

e-mail: BILLY.BOURKE@ucd.ie

Children's Research Centre, Our Lady's Hospital for Sick Children and Department of Paediatrics, The Conway Institute of Biomolecular and Biomedical Research, University College Dublin, Crumlin, Dublin 12, Ireland

\begin{abstract}
Campylobacter upsaliensis is an emerging human enteropathogen. However, little is known about the pathogenesis of $C$. upsaliensis infection. In this study the authors demonstrate that $C$. upsaliensis whole-cell preparations and extracts produce a cytolethal distending toxin (CDT)-like effect on HeLa cells characterized by progressive distension and nuclear fragmentation culminating in cell death over $5 \mathrm{~d}$. To further delineate the nature of this toxic effect in relation to CDT from other pathogens, the effect of $C$. upsaliensis on cellular events in epithelial cells and immunocytes was investigated. $C$. upsaliensis lysate-treated HeLa cells subjected to FACScan analysis using carboxyfluorescein diacetete succinimidyl ester (CFDA-SE) as a cell tracer demonstrated cell division arrest. Propidium iodide (PI) staining of HeLa cells revealed that cell cycle arrest occurred in $G_{2} / M$. Human $T$ lymphocytes exposed to $C$. upsaliensis lysates also showed cell cycle arrest in $G_{2} / M$. Using a combination of Annexin V/PI staining and TUNEL assay, cytodistended HeLa cells were shown to undergo apoptotic cell death. These data provide the first insights into the virulence mechanisms of this novel enteropathogen.
\end{abstract}

Keywords: enteropathogen, CDT, virulence factors, apoptosis

\section{INTRODUCTION}

Campylobacter upsaliensis is a recently described member of the genus Campylobacter that has been associated with enteric infection in humans (Steele et al., 1985; Patton et al., 1989; Lindblom et al., 1995; Jimenez et al., 1999). The precise prevalence of C. upsaliensis-associated diarrhoea is uncertain because this species is sensitive to antibiotics present in Campylobacter-selective media used in most clinical laboratory settings. However, when specifically sought using specially devised media or a filtration technique C. upsaliensis accounts for up to $20 \%$ of all Campylobacter isolates identified from stools (Bourke et al., 1998). C. upsaliensis is particularly common in some groups, including those who are immunocomprised (Patton et al., 1989; Jenkin \& Tee, 1998), and among children (Lindblom et al., 1995; Lastovica \& LeRoux, 1993). C. upsaliensis has been associated with extra-enteric infections including septicaemia (Patton et al., 1989; Chusid et al., 1990),

Abbreviations: CDT, cytolethal distending toxin; CFDA-SE, carboxyfluorescein diacetete succinimidyl ester; CFSE; carboxyfluorescein succinimidyl ester; PHA, phytohaemagglutinin; Pl, propidium iodide. haemolytic-uremic syndrome (Carter \& Cimolai, 1996) and more recently Guillain-Barre syndrome (Goddard et al., 1997; Ho et al., 1997).

Despite considerable evidence for a role of C.upsaliensis in human disease, little is known of the molecular biology or pathogenic mechanisms of this organism (Bourke et al., 1995, 1996, 1998). In particular, few studies have investigated the mechanisms by which $C$. upsaliensis causes disease. It is known that the organism is motile and adheres to tissue culture cells in vitro (Bourke et al., 1998). However, the mechanisms underlying adhesion and its contribution to virulence have not been explored.

There have been few reports of the investigation of toxin activity in C. upsaliensis (Bourke et al., 1998). However, Pickett et al. (1996) noted both the presence of a cytolethal distending toxin B gene $(c d t B)$ homologue and cytolethal distending toxin (CDT) activity in the $C$. upsaliensis type strain. Furthermore, CDT activity was demonstrated for two C. upsaliensis strains isolated from children with diarrhoea in Italy (Musmanno et al., 1998). CDT, first described by Johnson \& Lior (1988) is produced by a number of bacterial pathogens, including 
Escherichia coli (Scott \& Kaper, 1994; Pickett et al., 1996; Peres et al., 1997), Shigella species (Okuda et al., 1997), Haemophilus ducreyi (Cope et al., 1997), Actinobacillus actinomycetemcomitans (Sugai et al., 1998) and Campylobacter jejuni (Pickett et al., 1996; Purdy et al., 2000). This toxin alters host cell cytoskeletal structure (Aragon et al., 1997) and causes cell cycle arrest in epithelial cells (Peres et al., 1997; Whitehouse et al., 1998) and T cells (Shenker et al., 1999; Gelfanova et al., 1999) through its effect on cyclin-dependent kinases (Comayras et al., 1997; Whitehouse et al., 1998). Because preliminary reports suggested that C. upsaliensis also harbours a CDT-like activity we investigated the effects of this species on tissue culture cells and human T cells.

\section{METHODS}

Bacterial strains media and culture. The bacterial isolates used in this study are indicated in Table 1. The C. upsaliensis isolates comprised four human clinical strains obtained from the Laboratory Centre For Disease Control, Winnipeg, Canada, and the ATCC type strain. For the toxin and hybridization studies, isolates of Campylobacter jejuni and Helicobacter pylori (Table 1) were used as positive and negative controls, respectively. Campylobacter and Helicobacter strains were grown on Columbia blood agar plates at $37^{\circ} \mathrm{C}$ under microaerobic conditions.

Preparation of bacterial lysate and cell culture supernate. $C$. upsaliensis organisms were harvested from blood agar plates in RPMI 1640 cell culture medium. The volume of medium used was adjusted so that the $\mathrm{OD}_{600}$ of the bacterial suspension was $0 \cdot 125\left(2 \times 10^{8}\right.$ c.f.u. $\left.\mathrm{ml}^{-1}\right)$. Bacteria were centrifuged at 4800 r.p.m. for $10 \mathrm{~min}$ and the supernatant collected. The bacterial pellet was resuspended in RPMI 1640 tissue culture medium and the bacteria lysed by sonication $(4 \times 30 \mathrm{~s}$ bursts with $30 \mathrm{~s}$ intervals between each burst). Cell debris and unlysed bacteria were then removed by centrifugation, 10000 r.p.m. for $20 \mathrm{~min}$. Bacterial supernate and cell lysate were sterilized by passage through a $0 \cdot 2 \mu \mathrm{m}$ filter, split into aliquots and stored at $-20{ }^{\circ} \mathrm{C}$.

Detection of cytotoxic activity in culture supernatants and

Table 1. Bacterial strains used in this study

\begin{tabular}{|llll|}
\hline Species & Strain no. & $\begin{array}{c}\text { Isolated } \\
\text { from }\end{array}$ & Source* \\
\hline C. upsaliensis & ATCC 43954 & Dog & ATCC \\
C. upsaliensis & 17234 & Human & LCDC \\
C. upsaliensis & 17237 & Human & LCDC \\
C. upsaliensis & 17282 & Human & LCDC \\
C. upsaliensis & 17283 & Human & LCDC \\
C. jejuni & ATCC 33291 & Human & ATCC \\
H. pylori & PU3 & Human & OLHSC \\
\hline
\end{tabular}

*ATCC, American Type Culture Collection, Manassas, VA, USA; LCDC, Laboratory Centre For Disease Control, Winnipeg, Canada; OLHSC, Our Lady's Hospital For Sick Children, Dublin. bacterial lysates. HeLa cells were grown to confluence at $37^{\circ} \mathrm{C}$ in RPMI 1640 tissue culture medium containing $5 \%$ fetal calf serum. Cells were trypsinized and seeded into 24 -well tissue culture plates at a density of $2.5 \times 10^{4}$ cells per well in $500 \mu \mathrm{l}$ medium. Cells were allowed to attach to the base of the wells overnight prior to addition of C. upsaliensis organisms, culture supernate or bacterial lysate. Doubling dilutions of the bacterial cultures, supernate and lysate were made and $500 \mu \mathrm{l}$ amounts added to the wells; the plates were then incubated at $37^{\circ} \mathrm{C}$ in an atmosphere of $5 \% \mathrm{CO}_{2}$ for up to $5 \mathrm{~d}$. For experiments using unlysed bacteria, $500 \mu \mathrm{l}$ of organisms (equivalent to $1 \times 10^{8}$ c.f.u.) suspended in RPMI were incubated for $4 \mathrm{~h}$ with HeLa cells and then the suspension was removed and replaced with tissue culture medium. Each day a plate was removed from the incubator and morphological changes in the cells were examined by Giemsa staining and microscopy. Toxin titres were expressed as the reciprocal of the highest dilution that distended $50-70 \%$ of cells in the well. Toxin assays were performed in duplicate.

Demonstration of HeLa cell nuclear changes. HeLa cells $\left(2.5 \times 10^{5}\right)$ were grown on glass coverslips for $24 \mathrm{~h}$ prior to the addition of cell lysate. At daily intervals cells were stained with ethidium bromide and acridine orange; the coverslips were mounted in DPX and subsequently cells were viewed by fluorescence microscopy.

Demonstration of cell cycle arrest. HeLa cells were grown overnight in $25 \mathrm{~cm}^{2}$ flasks $\left(5 \times 10^{5}\right.$ cells per flask). The following day, cells were labelled with carboxyfluorescein diacetete succinimidyl ester (CFDA-SE; Molecular Probes). After diffusion into host cells CFDA-SE undergoes acetate modification. The probe is colourless and non-fluorescent until its acetate groups are cleaved by intracellular esterases to yield highly fluorescent, amine-reactive carboxyfluorescein succinimidyl ester (CFSE). The dye-protein adducts that form in labelled cells are retained by the cells throughout development. After each cell division the amount of label inherited by the daughter cells is halved. Cells were washed with prewarmed PBS $\left(37^{\circ} \mathrm{C}\right)$ containing the CFDA-SE probe $(0.01 \mathrm{mM})$ and incubated at $37^{\circ} \mathrm{C}$ for $15 \mathrm{~min}$. The probe was replaced with fresh prewarmed cell culture medium and cells were further incubated for $30 \mathrm{~min}$ at $37^{\circ} \mathrm{C}$. Cell lysate was then added to the cells. At daily intervals a flask of cells was removed from the incubator, trypsinized, and fluorescence of the cells monitored using flow cytometry. A total of 10000 events was collected and analysed using the LYSIS II software from Becton Dickinson.

Cell cycle arrest of HeLa cells was also monitored by propidium iodide (PI) staining of lysate-treated cells. Cells were removed from the flasks by trypsinization, and stained with PI using the DNAcon3 (Consul TS, TO, Italy) kit according to the manufacturer's instructions. Flow cytometry analysis of the DNA content of the cells was performed with a FACScan flow cytometer (Becton Dickinson). Data from 50000 cells were collected and analysed using the LYSIS II software. The signal of orange fluorescence (FL2, corresponding to PI) was measured by linear amplification.

Human $T$ cell isolation and demonstration of $T$ cell cycle alteration. Venous peripheral blood was obtained from healthy adult volunteers. Mononuclear cells were isolated by Ficol Hypaque (Lymphoprep, Nycomed, Norway) densitygradient centrifugation and resuspended in Lymphoquik $\mathrm{T}$ cell (VH Bio, UK) for $45 \mathrm{~min}$ at $37^{\circ} \mathrm{C}$ to deplete $\mathrm{B}$ cells and monocytes. By comparing anti-CD45:anti-CD3 ratios using FACScan analysis the resulting populations were shown to be $>90 \% \mathrm{CD} 3+$. 

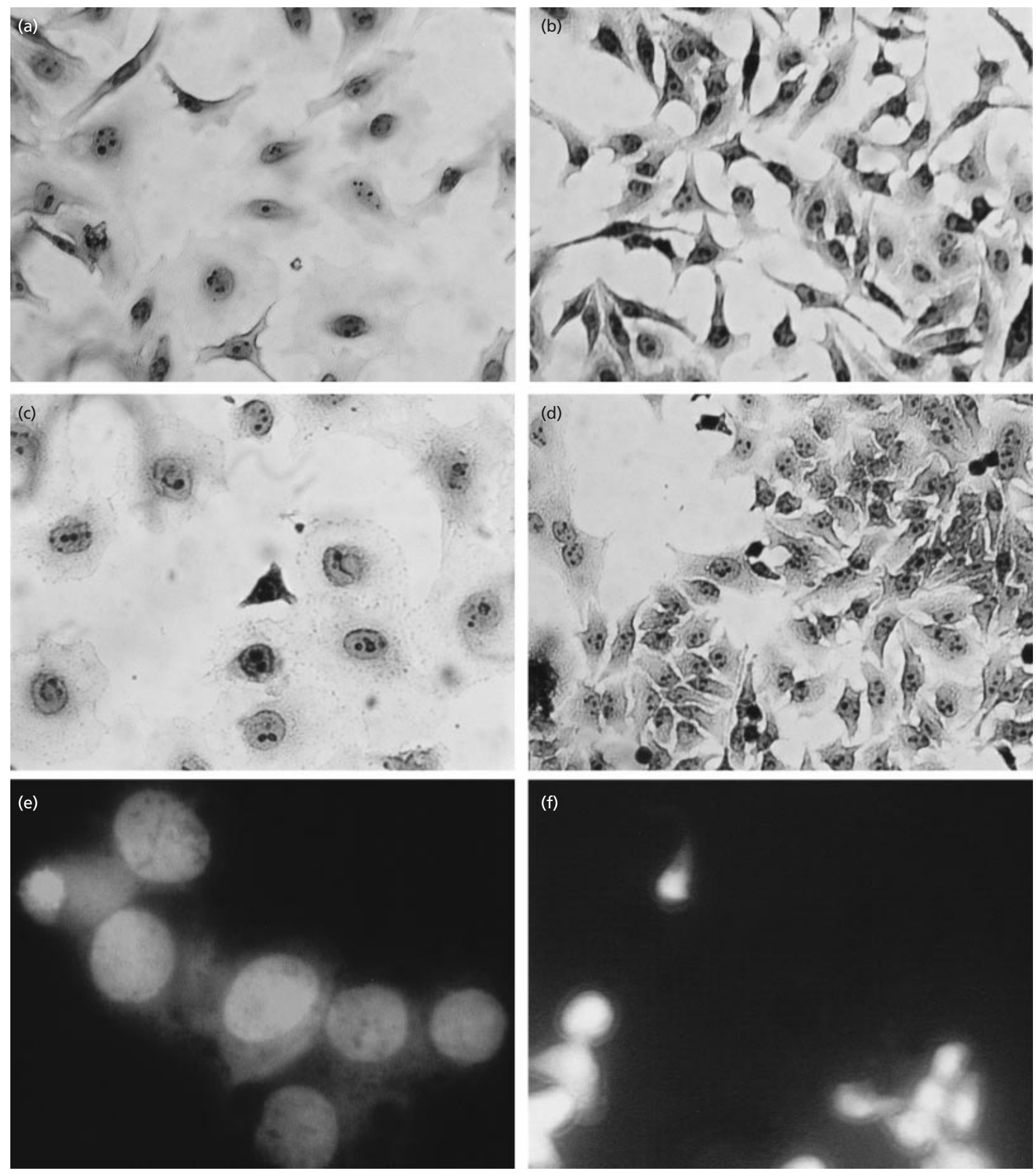

Fig. 1. Effect of $C$. upsaliensis on morphology of HeLa cells. (a-d) Giemsa staining of HeLa cells after interaction with $C$. upsaliensis ATCC 43954 lysate for $24 \mathrm{~h}$ (a) and $72 \mathrm{~h}$ (c), compared with untreated control cells at $24 \mathrm{~h}$, (b); and $72 \mathrm{~h}$, (d) respectively. (e, f) Acridine orange/ethidium bromide staining of HeLa cells $72 \mathrm{~h}$ after interaction with $C$. upsaliensis 17234 lysate $(e)$ and $H$. pylori PU3 lysate $(f)$. Magnification $\times 170(a-d), \times 425(e, f)$.

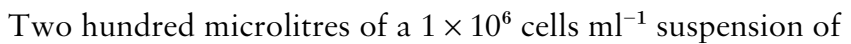
cells were cultured in 96-well plates with phytohaemagglutinin (PHA; $10 \mu \mathrm{g} \mathrm{ml}^{-1}$, Sigma-Aldrich) in RPMI 1640 supple- mented with glutamine, gentamicin and $10 \%$ fetal calf serum in the presence and absence of C. upsaliensis lysate. The cells were incubated for $72 \mathrm{~h}$ at $37^{\circ} \mathrm{C}$ in a humidified incubator 


\section{Table 2. CDT activity of lysates of $C$. upsaliensis isolates}

Titre values represent the reciprocal of the highest dilution at which $50 \%$ or more cells exhibited morphological changes of enlargement and distension.

\begin{tabular}{|rrrrrr|}
\hline Day & \multicolumn{5}{c|}{ Titre with lysate from: } \\
\cline { 2 - 6 } & $\mathbf{1 7 2 3 4}$ & $\mathbf{1 7 2 3 7}$ & $\mathbf{1 7 2 8 2}$ & $\mathbf{1 7 2 8 3}$ & ATCC \\
& & & & & $\mathbf{4 3 9 5 4}$ \\
\hline 1 & 8 & 4 & 16 & 8 & 32 \\
2 & 128 & 6 & 128 & 64 & 256 \\
3 & 256 & 128 & 256 & 128 & 1024 \\
4 & 512 & 128 & 256 & 256 & 1024 \\
5 & 512 & 128 & 256 & 256 & 1024 \\
\hline
\end{tabular}

containing $5 \% \mathrm{CO}_{2}$, harvested and analysed by flow cytometry for cell cycle arrest using PI and CFSE. Individual flow cytometry experiments were repeated at least twice.

TUNEL assay and Annexin V/PI staining. For the TUNEL assay, HeLa cells treated with cell lysate were probed at $24 \mathrm{~h}$ intervals up to $5 \mathrm{~d}$ using BODIPY-FLX-14-dUTP probe (Molecular Probes), according to the manufacturer's instructions. Briefly, HeLa cells on mounted coverslips were overlaid with $200 \mu$ reaction medium consisting of TdT buffer solution (1 M potassium cacodylate, $125 \mathrm{mM}$ Tris $/ \mathrm{HCl}, 1 \cdot 26$ ng BSA ml${ }^{-1}$ ), $2.5 \mathrm{mM} \mathrm{CoCl}_{2}, 50 \mathrm{U} \mathrm{TdT} \mathrm{(Boehringer)} \mathrm{and} 1$
nM BODIPY-FLX-14-dUTP. Coverslips were incubated for $1 \mathrm{~h}$ at $37^{\circ} \mathrm{C}$ in humidified chambers, washed with PBS, airdried and viewed using UV microscopy. Untreated HeLa cells served as controls.

For Annexin V/PI staining, cells treated with cell lysate were removed from tissue culture flasks by trypsinization, washed twice in cold PBS and resuspended in binding buffer $(10 \mathrm{mM}$ HEPES/NaOH pH 7.4, $140 \mathrm{mM} \mathrm{NaCl}, 2.5 \mathrm{mM} \mathrm{CaCl}_{2}$ ) at a concentration of $10^{6}$ cells ml $^{-1}$. One hundred microlitres of cells was transferred to a FACScan tube to which was added $10 \mu \mathrm{l}$ of a $10 \mu \mathrm{g} \mathrm{ml}^{-1}$ fluorescein-conjugated Annexin V solution (IQ Corp, Groningen, Netherlands) and $10 \mu \mathrm{l}$ of a $50 \mu \mathrm{g} \mathrm{ml}^{-1}$ PI solution. Annexin V is a phosphatidylserinebinding protein that detects phosphatidylserine on the surface of cells undergoing apoptosis, whereas PI associates with nuclear DNA, indicating necrotic cell death. Cells were vortexed gently and then incubated at room temperature for $15 \mathrm{~min}$ in the dark. Then $400 \mu \mathrm{l}$ binding buffer was added to the cells and they were analysed by flow cytometry within $1 \mathrm{~h}$ of staining. The data from 10000 cells were collected and analysed using the LYSIS II software. The signals of green fluorescence (FL1; Annexin V) and orange fluorescence (FL2; PI) were measured by logarithmic amplification.

\section{RESULTS}

\section{Effect of C. upsaliensis lysates on the cell cycle}

Initially we examined the effect of a variety of $C$. upsaliensis isolates on HeLa cells. As shown in Fig. $1(\mathrm{a}-\mathrm{d})$, C. upsaliensis ATCC 43954 lysates produced

(a)

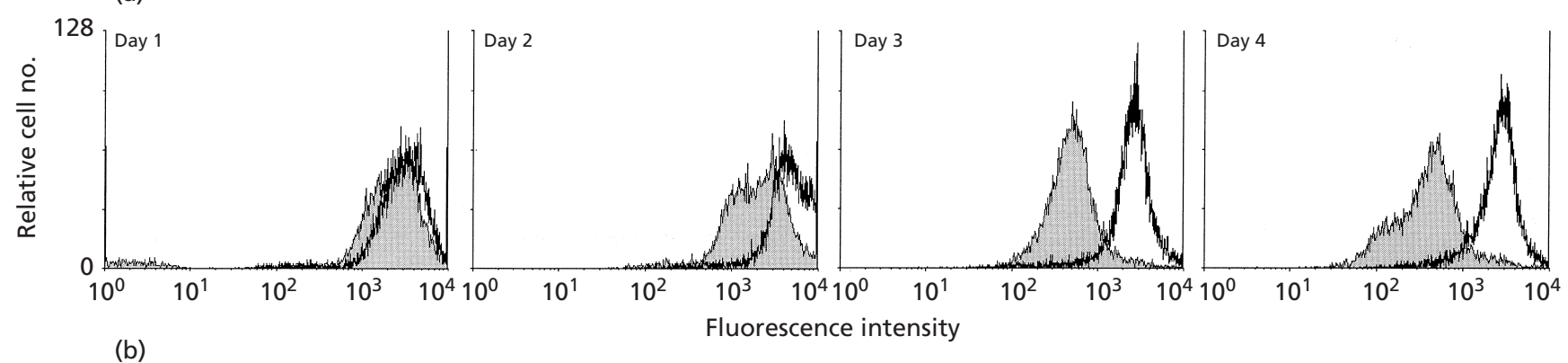

(b)

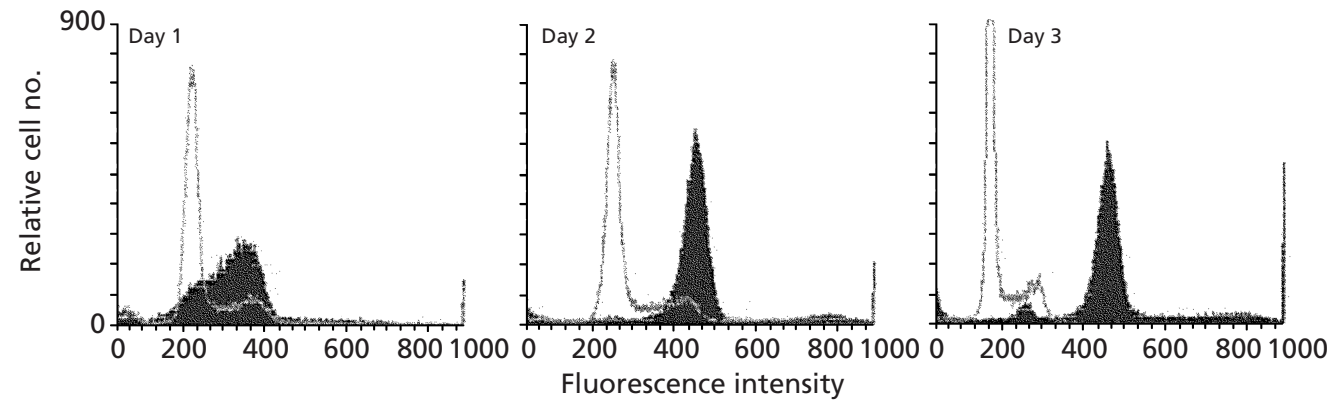

Fig. 2. (a) Cell cycle analysis of HeLa cells following interaction with C. upsaliensis ATCC 43954 lysates (open peaks) compared with untreated control cells (shaded peaks) using CFSE staining, at the indicated times. HeLa cells exposed to bacterial lysates show unaltered fluorescence intensity throughout the observation period. In contrast, untreated HeLa cells show decreasing fluorescence intensity as the fluorescent dye is progressively partitioned into daughter cells over the $4 \mathrm{~d}$ time period. (b) Induction of $\mathrm{G}_{2} / \mathrm{M}$ block in HeLa cells by C. upsaliensis ATCC 43954 lysates (shaded peaks) compared with uninfected control cells (open peaks) using Pl staining. Flow cytometer settings were adjusted to have $\mathrm{G}_{1}$ ( $2 n$ DNA) and $\mathrm{G}_{2} / \mathrm{M}$ (4n DNA) at approximatedly 250 and 500 fluorescence units, respectively. There is accumulation of lysate-exposed HeLa cells in $\mathrm{G}_{2} / \mathrm{M}$ from day 2 . In contrast, $98 \%$ of untreated cells remained in $\mathrm{G}_{1}$ by day 3 . 
(a)

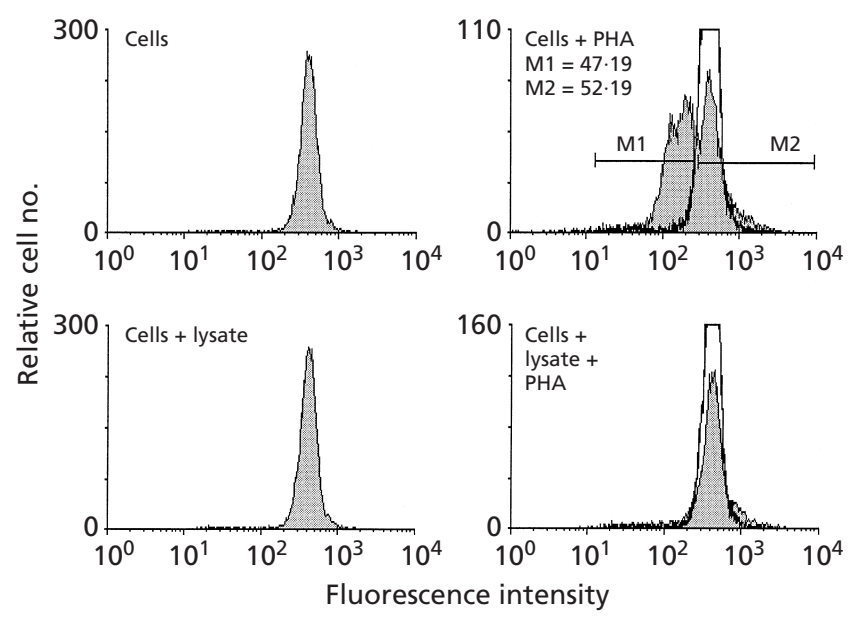

(b)

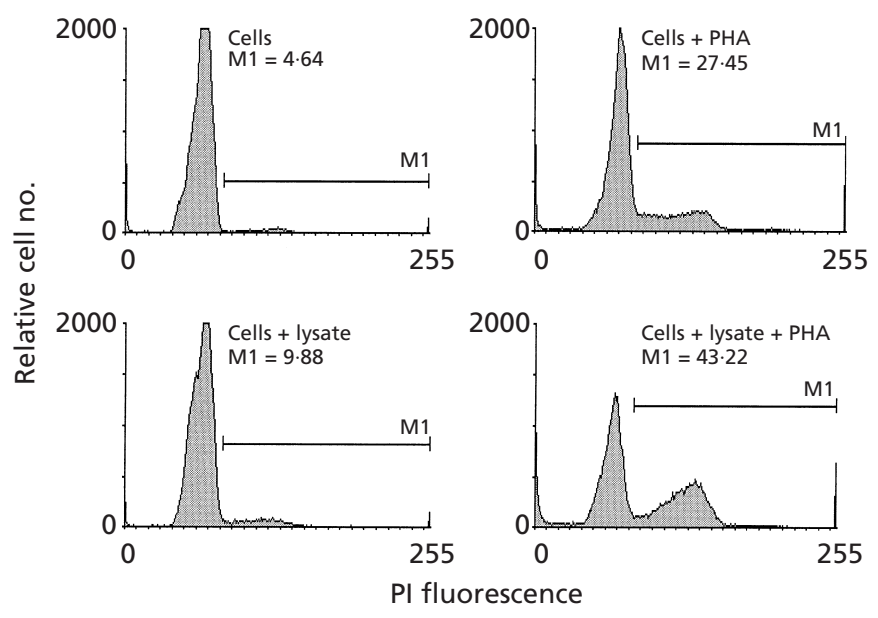

Fig. 3. (a) Human $T$ cells labelled with CFSE $72 \mathrm{~h}$ after stimulation with PHA in the presence or absence of $C$. upsaliensis ATCC 43954 lysate. The open peak superimposed on the graphs of PHA-stimulated T cells (both lysate-treated and untreated) represents the unstimulated $T$ cell population in each case. The percentages of the original population of $T$ lymphocytes having undergone cell division (M1) and those remaining undivided (M2) are indicated for PHA-stimulated, lysate-untreated cells. Cells stimulated with PHA show a reduction in fluorescence intensity as cells divide, causing CFSE dye to be partitioned into daughter cells (top panel). In contrast, lysate-treated cells do not show stimulated cell division (bottom left) and cells treated with both lysate and PHA fail to divide, as evidenced by a single peak of fluorescence. (b) T cells stained with PI $72 \mathrm{~h}$ after exposure to C. upsaliensis ATCC 43954 lysates show an increased proportion of cells in $\mathrm{G}_{2} / \mathrm{M}$ compared with untreated control cells. Flow cytometer settings were adjusted to have $G_{1}\left(2 n\right.$ DNA) and $G_{2} / M^{2}(4 n$ DNA) at approximatedly 70 and 140 fluorescence units, respectively. The percentage of T cells in cell cycle (M1) is indicated. The top right panel shows that PHA stimulation of non-lysate-treated T cells causes a proportion of the cells to enter cell cycle, with a small peak in the $\mathrm{G}_{2} / \mathrm{M}(4 n \mathrm{DNA})$ region. In contrast, PHA-stimulated lysate-treated $\mathrm{T}$ cells demonstrate a large accumulation of cells in the $\mathrm{G}_{2} / \mathrm{M}(4 n$ DNA) region (bottom right panel). The addition of lysate alone did not affect cell division (bottom left panel).

progressive distension of HeLa cells. C. jejuni-treated HeLa cells showed the same phenotypic changes, whereas HeLa cells exposed to lysates from $H$. pylori were unaffected (data not shown). In addition to the type strain, four clinical isolates of C. upsaliensis obtained from human stool specimens (LCDC strains 17234, 17237, 17282 and 17283) were tested for toxicity. Lysates from all five C. upsaliensis strains tested showed a cytodistending effect on HeLa cells, with some variation in titre (Table 2). Acridine orange/ethidium bromide staining of HeLa cells exposed to each of the five $C$. upsaliensis strains demonstrated progressive nuclear distension (Fig. 1e), characteristic of CDT (Whitehouse et al., 1998; Sugai et al., 1998).

As CDT from other organisms (Whitehouse et al., 1998; Comayras et al., 1997; Sugai et al., 1998) interferes with cell cycle progression, we analysed the effect of $C$. upsaliensis lysates on HeLa cell division using CFSE as a probe. Fig. 2(a) shows that control HeLa cells unexposed to C. upsaliensis lysates (shaded peaks) underwent cell division, as evidenced by the progressive diminution of CFSE fluorescence intensity during day 1 to day 4 of incubation and the appearance of a second peak as the CFSE dye was inherited by daughter cells. Conversely, lysate exposed HeLa cells (represented by the open peaks in Fig. 2a) showed fluorescence intensity unaltered from day 1 to day 4, indicating arrest of cell division.
In order to determine in what phase the cell cycle arrest was occurring we undertook flow cytometry analysis of the DNA content of HeLa cells after PI staining. The results, shown in Fig. 2(b), indicate that the cells were blocked in $G_{2} / M$. The majority of control, untreated HeLa cells (open peaks) had $2 n$ DNA content, with a small peak at twice the fluorescence intensity representing dividing cells transiently in $\mathrm{G}_{2} / \mathrm{M}$ phase $(4 n$ DNA content). In comparison, lysate-exposed HeLa cells (shaded peaks) showed progressive accumulation of cells with $4 n$ DNA content. By 72 h, $70 \%$ of lysatetreated cells were in $\mathrm{G}_{2} / \mathrm{M}$, whereas less than $2 \%$ of untreated cells were in $\mathrm{G}_{2} / \mathrm{M}$.

A similar pattern of cell cycle arrest was also seen among human T cells exposed to C. upsaliensis lysates. After $72 \mathrm{~h}$, unstimulated cells (without PHA) had a single well-defined peak of high fluorescence intensity. Stimulation with PHA resulted in the appearance of a second peak of lower fluorescence intensity, indicating partitioning of CFSE dye into daughter cells. In contrast, lysate-treated cells stimulated with PHA did not show evidence of change in CFSE intensity, indicating almost complete abrogation of cell division (Fig. 3a). PI staining demonstrated that, in the absence of lysate, a proportion $(27 \%)$ of PHA-stimulated T cells enter into the cell cycle, as evidenced by the small peak of fluorescence in the $4 n$ DNA region $\left(G_{2} / M\right)$ (Fig. $3 b$, top panels). 
Table 3. CDT activities of bacterial cultures, supernatants and lysates of C. upsaliensis ATCC 43954

\begin{tabular}{|cccc|}
\hline Day & Bacteria* & Supernatant $\dagger$ & Lysate $\dagger$ \\
\hline 1 & $2 \cdot 0 \times 10^{8}$ & - & 32 \\
2 & $1 \cdot 3 \times 10^{7}$ & 64 & 256 \\
3 & $3 \cdot 9 \times 10^{5}$ & 64 & 1024 \\
4 & $2 \cdot 0 \times 10^{5}$ & 64 & 1024 \\
5 & $2 \cdot 0 \times 10^{5}$ & 64 & 1024 \\
\hline
\end{tabular}

* Lowest number of bacteria added to the cells at which $50 \%$ or more cells exhibited morphological changes of enlargement and distension.

† Titre values represent the reciprocal of the highest dilution at which $50 \%$ or more cells exhibited morphological changes of enlargement and distension.

However, cells stimulated to divide in the presence of bacterial lysate showed a larger population $(43 \%)$ in cell cycle and a substantial proportion of these were accumulating in $\mathrm{G}_{2} / \mathrm{M}$ phase (Fig. $3 \mathrm{~b}$, bottom right panel).

\section{Toxin effect of $C$. upsaliensis cultures, lysates and supernatants}

The toxic effect produced by bacterial lysates, whole bacteria and bacterial supernatants is shown in Table 3 . Unconcentrated C. upsaliensis supernatants demon- strated a very low titre of activity. However, a toxin effect was evident from both lysates and fresh cultures. The relative effects of lysates and cultures were similar after $96 \mathrm{~h}$ incubation for the type strain (Table 3 ) and equivalent results were seen among the four other $C$. upsaliensis isolates tested (data not shown).

\section{Demonstration of host cell apoptosis}

CDT-treated epithelial cells have been shown in previous studies to have morphological features suggestive of apoptotic cell death. In order to determine if cytodistended HeLa cells underwent apoptosis we used the TUNEL assay to detect nuclear DNA fragmentation, characteristic of this form of cell death. Increased host cell apoptosis was clearly evident $48 \mathrm{~h}$ after exposure of HeLa cells and the numbers of cells with apoptotic nuclear changes increased progressively up to $5 \mathrm{~d}$ after exposure. Immunofluorescence microscopy (Fig. 4a) clearly demonstrated strongly TUNEL-positive nuclei among lysate-treated HeLa cells. This contrasted with the background staining and occasional TUNEL-positive nucleus among control cells (Fig. 4b).

To further investigate the nature of host cell death following exposure to C. upsaliensis, cells treated with bacterial lysate were stained with a combination of Annexin V and PI. Flow cytometry analysis of affected cells demonstrated increased surface expression of phosphatidylserine, as evidenced by increased Annexin $\mathrm{V}$ binding, compared to control untreated cells (Fig. 5). At the same time, these cells continued to exclude PI,
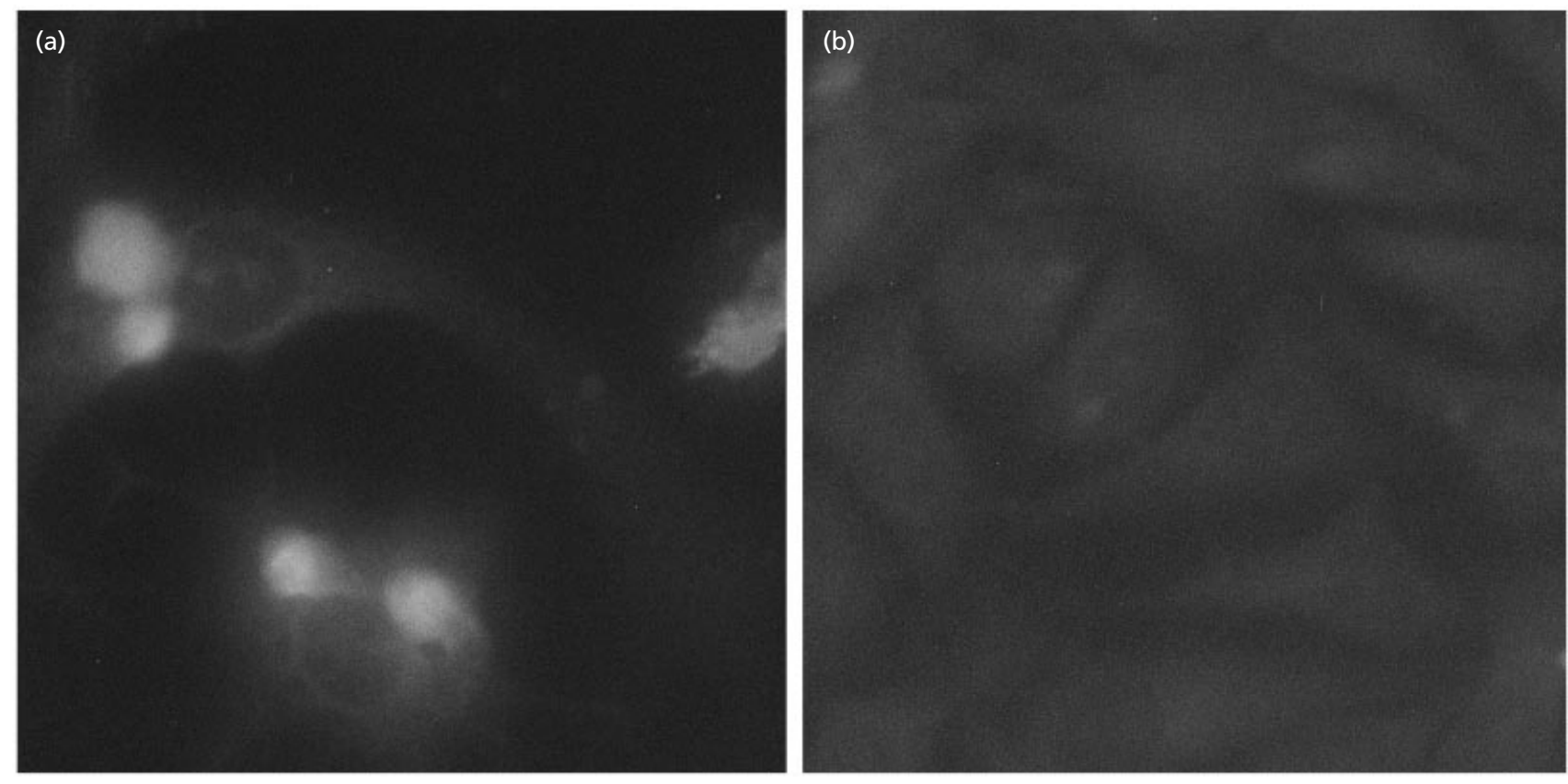

Fig. 4. (a) Fluorescence micrograph identifying apoptotic HeLa cells. At $96 \mathrm{~h}$ after exposure to C. upsaliensis ATCC 43954 lysates there are strongly fluorescent areas in the perinuclear region of cytodistended HeLa cells, indicating the presence of apoptotic (TUNEL-positive) DNA fragmentation. In contrast, untreated control cells (b) do not show TUNEL-positive nuclei. Magnification $\times 900$. 

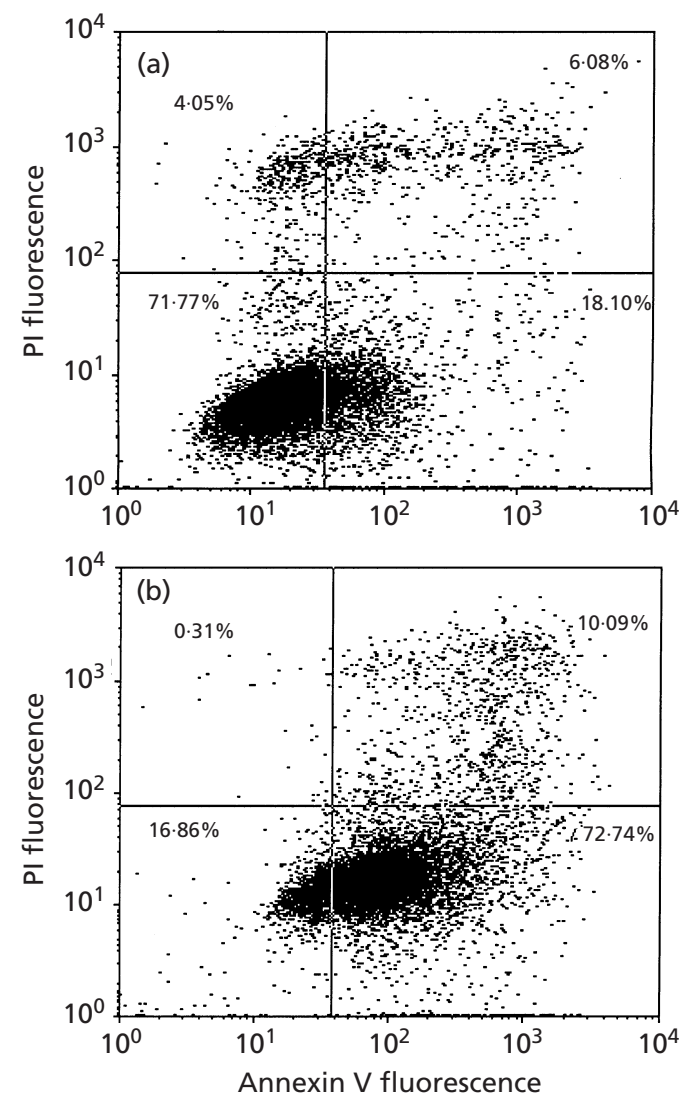

Fig. 5. Annexin V/PI staining of HeLa cells $48 \mathrm{~h}$ after exposure to lysates of C. upsaliensis ATCC 43954 (b) compared with uninfected control cells (a). Cells in the lower left of the cytogram are viable. Apoptotic cells in the lower right have increased Annexin V fluorescence without loss of viability. The percentages of cells in each quadrant are indicated.

which associates with the nuclear DNA of necrotic cells. Taken together these data clearly indicate that $C$. upsaliensis-lysate-treated, cytodistended HeLa cells undergo increased levels of apoptosis.

\section{DISCUSSION}

There exists considerable epidemiological evidence to support a substantial role for C. upsaliensis in human disease. However, partly because of the failure of commercially available Campylobacter-selective media to isolate this organism, C. upsaliensis is rarely isolated in clinical laboratories and is little known among clinicians (Bourke et al., 1998). Consequently, the pathogenesis of C. upsaliensis infection is largely unexplored and data on potential virulence factors for this organism are scarce.

To date, no C. upsaliensis virulence determinants have been characterized in detail. This enteropathogen has been shown to adhere to tissue culture cells and lipids in vitro (Sylvester et al., 1996). However, the bacterial factor(s) underlying cell adherence have not been ex- plored. Preliminary studies suggested that this organism may harbour CDT activity (Pickett et al., 1996; Musmanno et al., 1998). Therefore, we evaluated the effect of whole-cell preparations and lysates of $C$. upsaliensis on tissue culture cells and human T lymphocytes. We have observed cytodistension, nuclear fragmentation, cell cycle arrest and apoptosis in affected host cells, suggestive of a CDT-like effect.

Direct proof that the observed host cell phenotypes are the result of CDT will rely on the construction of isogenic $c d t$ mutant strains and comparison with wildtype organisms of their pathogenic effects. To date, despite intensive efforts, we have been unable to transform C. upsaliensis in order to construct isogenic mutant strains. Therefore, it is possible that the cytodistension, cell cycle arrest and cell death phenomena observed in this study are the result of bacterial factor(s) other than CDT. However, the characteristic nature of the C. upsaliensis-induced host cell events, coupled with the presence of $c d t$ genes in all of $30 \mathrm{C}$. upsaliensis strains that we have tested (unpublished data), strongly support the notion that this organism harbours a CDT and that this virulence factor is probably common to most, if not all, C. upsaliensis.

Although the relevance in vivo of CDT is uncertain, Okuda et al. (1995) demonstrated watery diarrhoea following CDT administration in a suckling mouse model. Recently, Purdy et al. (2000) have shown that C. jejuni isogenic $c d t$ mutants had reduced invasiveness in a mouse model of enteric infection. Furthermore, Albert et al. (1996) found CDT-positive E. coli strains more commonly among children with diarrhoea than among those without diarrhoea. C. upsaliensis produces selflimiting, watery diarrhoea in the majority of affected patients, whereas inflammatory diarrhoea with blood and leucocytes occurs infrequently (Jimenez et al., 1999; Bourke et al., 1998). Taken together these clinical and laboratory observations support the notion that $C$. upsaliensis diarrhoeal disease is caused, at least in part, by a toxin-induced increase in intestinal fluid secretion. CDT represents a potential candidate for this effect.

Compared with bacterial lysates C. upsaliensis supernatants had low or absent toxic effects in this assay (Pickett et al., 1996). However, we have shown that cytodistending toxin effects are also produced when HeLa cells are exposed to fresh cultures of C.upsaliensis. It is difficult to draw meaningful conclusions from a direct comparison of the toxin activity induced by $C$. upsaliensis bacterial cultures and those from sonicated lysates. However, our data are consistent with the notion that the CDT activity is localized in the bacterial outer membrane, a site recently implicated for the CDT of C. jejuni (Hickey et al., 1999). An alternative explanation is that toxin secretion can be induced on contact with host cells. Current experiments in our laboratory are aimed at addressing this question.

CDT has been reported previously to induce cell cycle arrest in cells of non-epithelial origin. For instance the periodontal pathogen A. actinomycetemcomitans pro- 
duces a cell-cycle-inhibitory factor encoded by a $c d t$ gene cluster (Sugai et al., 1998) and this CDT effect appears to be responsible for $\mathrm{G}_{2} \mathrm{M}$ arrest in $\mathrm{T}$ cells (Shenker et al., 1999). More recently, H. ducreyi CDT has been implicated as a cause of $\mathrm{T}$ cell cycle inhibition and apoptosis (Gelfanova et al., 1999). Our present report shows that C. upsaliensis lysates can induce $G_{2} M$ phase arrest in $\mathrm{T}$ cells. These preliminary observations require further study in order to confirm the nature of the cell-cycle-inhibitory factor involved and the precise subpopulation of $\mathrm{T}$ cells targeted by this effect. However, these data suggest that C. upsaliensis, and perhaps other enteric campylobacters, may be able to modulate the local immune response in the intestine during the infection process. To our knowledge, modulation of the immune response by an enterobacterial toxin effect has not previously been reported.

The precise mechanism underlying CDT-mediated cell death is not defined. Recently, DeRycke et al. (2000) described multi-polar abortive mitosis and a micronucleation process as lethal events in CDT-exposed HeLa cells. Previously, immunofluorescence studies showed that abnormal chromatin condensation and nuclear fragmentation occurs during cell death following exposure to CDT (Whitehouse et al., 1998). This appearance, also observed in HeLa cells following treatment with other bacterial CDTs (Sugai et al., 1998), is reminiscent of apoptotic cell death. However, whether CDT-treated epithelial cells ultimately die through an apoptotic mechanism remains to be proven. A cytotoxicnecrotizing-factor-producing strain of E. coli also with CDT activity, BM2-1, induces apoptotic cell death (De Rycke et al., 1996). It is also noteworthy that C. jejuni outer-membrane proteins cause apoptosis of chicken lymphocytes (Zhu et al., 1999). Furthermore, H. ducreyi CDT is responsible for apoptosis in Jurkat cells (Gelfanova et al., 1999), and A. actinomycetemcomitans causes murine macrophage apoptosis (Kato et al., 1995). In the present study we examined HeLa cells treated with C. upsaliensis lysate for apoptosis using the TUNEL assay. The presence of apoptotic DNA fragmentation among affected cells was clearly evident among cytodistended, lysate-exposed HeLa cells after 48 h. Dual Annexin V/PI staining further confirmed that cytodistended cells predominantly undergo apoptosis rather than necrosis (Fig. 5). Given the importance of programmed cell death as a homeostatic mechanism for maintaining the balance of intestinal epithelial cells, the host cell mechanism(s) underlying C. upsaliensis-induced apoptosis and its relevance in vivo will be an important area for future investigation.

In summary, we have shown that C. upsaliensis cell lysates produce epithelial cell cytodistension and cell cycle arrest occurs both in tissue culture cells and in human $\mathrm{T}$ cells, effects characteristic of CDT. We also have confirmed that cytodistended epithelial cells undergo apoptosis. These data provide the first insights into the potentially complex interactions that underly the aetiopathogenesis of enteric infection by this emerging bacterial pathogen.

\section{ACKNOWLEDGEMENTS}

The authors wish to thank Drs David Woodward and Frank Rodgers from the Laboratory Centre For Disease Control, Winnipeg, Canada, for providing C. upsaliensis strains. We also thank Sharon Kearney and Petra Jansen for help in preparing this manuscript.

This work was supported by funding from The Children's Medical and Research Foundation and The Health Research Board, Ireland.

\section{REFERENCES}

Albert, M. J., Faruque, S. M., Faruque, A. S., Bettelheim, K. A., Neogi, P. K., Bhuiyan, N. A. \& Kaper, J. B. (1996). Controlled study of cytolethal distending toxin-producing Escherichia coli infections in Bangladeshi children. J Clin Microbiol 34, 717-719.

Aragon, V., Chao, K. \& Dreyfus, L. A. (1997). Effect of cytolethal distending toxin on F-actin assembly and cell division in Chinese hamster ovary cells. Infect Immun 65, 3774-3780.

Bourke, B., Sherman, P., Louie, H., Hani, E., Islur, P. \& Chan, V. L. (1995). Physical and genetic map of the genome of Campylobacter upsaliensis. Microbiology 141, 2417-2424.

Bourke, B., al Rashid, S. T., Bingham, H. L. \& Chan, V. L. (1996). Characterization of Campylobacter upsaliensis fur and its localization in a highly conserved region of the Campylobacter genome. Gene 183, 219-224.

Bourke, B., Chan, V. L. \& Sherman, P. (1998). Campylobacter upsaliensis: waiting in the wings. Clin Microbiol Rev 11, 440-449.

Carter, J. E. \& Cimolai, N. (1996). Hemolytic-uremic syndrome associated with acute Campylobacter upsaliensis gastroenteritis. Nephron 74, 489.

Chusid, M. J., Wortmann, D. W. \& Dunne, W. M. (1990). 'Campylobacter upsaliensis' sepsis in a boy with acquired hypogammaglobulinemia. Diagn Microbiol Infect Dis 13, 367-369.

Comayras, C., Tasca, C., Peres, S. Y., Ducommun, B., Oswald, E. \& De Rycke, J. (1997). Escherichia coli cytolethal distending toxin blocks the HeLa cell cycle at the G2/M transition by preventing cdc2 protein kinase dephosphorylation and activation. Infect Immun 65, 5088-5095.

Cope, L. D., Lumbley, S., Latimer, J. L. \& 8 other authors (1997). A diffusible cytotoxin of Haemophilus ducreyi. Proc Natl Acad Sci US A 94, 4056-4061.

De Rycke, J., Mazars, P., Nougayrede, J. P., Tasca, C., Boury, M., Herault, F., Valette, A. \& Oswald, E. (1996). Mitotic block and delayed lethality in HeLa epithelial cells exposed to Escherichia coli BM2-1 producing cytotoxic necrotizing factor type 1. Infect Immun 64, 1694-1705.

DeRycke, J., Sert, V., Comayras, C. \& Tasca, C. (2000). Sequence of lethal events in HeLa cells exposed to the G2 blocking cytolethal distending toxin. Eur J Cell Biol 79, 192-201.

Gelfanova, V., Hansen, E. J. \& Spinola, S. M. (1999). Cytolethal distending toxin of Haemophilus ducreyi induces apoptotic death of Jurkat T cells. Infect Immun 67, 6394-6402.

Goddard, E. A., Lastovica, A. J. \& Argent, A. C. (1997). Campylobacter $\mathrm{O}: 41$ isolation in Guillain-Barre syndrome. Arch Dis Child 76, 526-528.

Hickey, T. E., McVeigh, S. A., Carroll, S. A., Bourgeois, A. L. \& Guerry, P. (1999). Biological properties of cytolethal distending toxin. 10th International Workshop on Campylobacter, Helicobacter and Related Organisms, Baltimore, MD, abstract CP34.

Ho, T. W., Hsieh, S. T., Nachamkin, I. \& 8 other authors (1997). Motor nerve terminal degeneration provides a potential mech- 
anism for rapid recovery in acute motor axonal neuropathy after Campylobacter infection. Neurology 48, 717-724.

Jenkin, G. A. \& Tee, W. (1998). Campylobacter upsaliensisassociated diarrhea in human immunodeficiency virus-infected patients. Clin Infect Dis 27, 816-821.

Jimenez, S. G., Heine, R. G., Ward, P. B. \& Robins-Browne, R. M. (1999). Campylobacter upsaliensis gastroenteritis in childhood. Pediatr Infect Dis J 18, 988-992.

Johnson, W. M. \& Lior, H. (1988). A new heat-labile cytolethal distending toxin (CLDT) produced by Campylobacter spp. Microb Pathog 4, 115-126.

Kato, S., Muro, M., Akifusa, S., Hanada, N., Semba, I., Fujii, T., Kowashi, Y. \& Nishihara, T. (1995). Evidence for apoptosis of murine macrophages by Actinobacillus actinomycetemcomitans infection. Infect Immun 63, 3914-3919.

Lastovica, A. J. \& LeRoux, E. (1993). Prevalence of Campylobacter spp. in the diarrhoeic stools and blood cultures of pediatric patients. Acta Gastroenterol Belg 56 (suppl.), 34.

Lindblom, G. B., Sjogren, E., Hansson-Westerberg, J. \& Kaijser, B. (1995). Campylobacter upsaliensis, C. sputorum sputorum and C. concisus as common causes of diarrhoea in Swedish children. Scand J Infect Dis 27, 187-188.

Musmanno, R. A., Russi, M., Figura, N., Guglielmetti, P., Zanchi, A., Signori, R. \& Rossolini, A. (1998). Unusual species of campylobacters isolated in the Siena Tuscany area, Italy. New Microbiol 21, 15-22.

Okuda, J., Kurazono, H. \& Takeda, Y. (1995). Distribution of the cytolethal distending toxin A gene $(c d t A)$ among species of Shigella and Vibrio, and cloning and sequencing of the $c d t$ gene from Shigella dysenteriae. Microb Pathog 18, 167-172.

Okuda, J., Fukumoto, M., Takeda, Y. \& Nishibuchi, M. (1997). Examination of diarrheagenicity of cytolethal distending toxin: suckling mouse response to the products of the $c d t A B C$ genes of Shigella dysenteriae. Infect Immun 65, 428-433.

Patton, C. M., Shaffer, N., Edmonds, P., Barrett, T. J., Lambert, M. A., Baker, C., Perlman, D. M. \& Brenner, D. J. (1989). Human disease associated with 'Campylobacter upsaliensis' (catalasenegative or weakly positive Campylobacter species) in the United States. J Clin Microbiol 27, 66-73.

Peres, S. Y., Marches, O., Daigle, F., Nougayrede, J. P., Herault, F., Tasca, C., De Rycke, J. \& Oswald, E. (1997). A new cytolethal distending toxin (CDT) from Escherichia coli producing CNF2 blocks HeLa cell division in G2/M phase. Mol Microbiol 24, 1095-1107.

Pickett, C. L., Pesci, E. C., Cottle, D. L., Russell, G., Erdem, A. N. \& Zeytin, H. (1996). Prevalence of cytolethal distending toxin production in Campylobacter jejuni and relatedness of Campylobacter sp. cdtB gene. Infect Immun 64, 2070-2078.

Purdy, D., Buswell, C. M., Hodgson, A. E., McAlpine, K., Henderson, I. \& Leach, S. A. (2000). Characterisation of cytolethal distending toxin (CDT) mutants of Camplylobacter jejuni. J Med Microbiol 49, 473-479.

Scott, D. A. \& Kaper, J. B. (1994). Cloning and sequencing of the genes encoding Escherichia coli cytolethal distending toxin. Infect Immun 62, 244-251.

Shenker, B. J., McKay, T., Datar, S. \& 7 other authors (1999). Actinobacillus actinomycetemcomitans immunosuppressive protein is a member of the family of cytolethal distending toxins capable of causing a G2 arrest in human T cells. J Immunol 162, 4773-4780.

Steele, T. W., Sangster, N. \& Lanser, J. A. (1985). DNA relatedness and biochemical features of Campylobacter spp. isolated in central and South Australia. J Clin Microbiol 22, 71-74.

Sugai, M., Kawamoto, T., Peres, S. Y., Ueno, Y., Komatsuzawa, H., Fujiwara, T., Kurihara, H., Suginaka, H. \& Oswald, E. (1998). The cell cycle-specific growth-inhibitory factor produced by Actinobacillus actinomycetemcomitans is a cytolethal distending toxin. Infect Immun 66, 5008-5019.

Sylvester, F. A., Philpott, D., Gold, B., Lastovica, A. \& Forstner, J. F. (1996). Adherence to lipids and intestinal mucin by a recently recognized human pathogen, Campylobacter upsaliensis. Infect Immun 64, 4060-4066.

Whitehouse, C. A., Balbo, P. B., Pesci, E. C., Cottle, D. L., Mirabito, P. M. \& Pickett, C. L. (1998). Campylobacter jejuni cytolethal distending toxin causes a G2-phase cell cycle block. Infect Immun 66, 1934-1940.

Zhu, J., Meinersmann, R. J., Hiett, K. L. \& Evans, D. L. (1999). Apoptotic effect of outer-membrane proteins from Campylobacter jejuni on chicken lymphocytes. Curr Microbiol 38, 244-249.

Received 7 August 2000; revised 27 October 2000; accepted 22 November 2000. 